\title{
RESENHA
}

\section{CONHECENDO ALGUMAS POSSIBILIDADES DE INSERÇÃO DAS QUESTÕES SOCIOCIENTÍFICAS E SOCIOTECNOLÓGICAS NA EDUCAÇÃO CIENTÍFICA E TECNOLÓGICA}

\author{
Elisangela Matias Miranda*
}

CONRADO, Dália Melissa; NUNES-NETO, Nei. (Orgs.) Questões Sociocientíficas: fundamentos, propostas de ensino e perspectivas para ações sociopolíticas. Salvador: EDUFBA, 2018. 570p.

$\mathrm{Na}$ atualidade, a ciência e a tecnologia, com seus desenvolvimentos e influências nas dimensões humana, social, cultural e econômica, passaram a constituir objetos de debates, sobre como discutir no ensino de ciências suas naturezas, suas potencialidades e seus limites, em função, entre outros fatores, de seus impactos em relação ao bem-estar da sociedade. Dentro deste contexto, umas das principais preocupações do ensino de ciências é a inserção de discussões sociocientíficas contemporâneas que possibilitem que os estudantes compreendam a ciência não apenas como um corpo de conhecimento sem controvérsias e que não requer e nem os convidam a uma argumentação crítica.

O problema surge, principalmente, das atividades que o ensino de ciências adota ao utilizar métodos tradicionais de transmissão e repetição de conteúdos com grande dependência de livros didáticos que visam à memorização e limitam a colaboração e a reflexão entre os alunos. Como um desafio às representações equivocadas da ciência e das práticas da ciência escolar, muitos educadores e pesquisadores advogam sobre a necessidade de incluir atividades que simulam as práticas discursivas da comunidade científica que se baseiam no desenvolvimento da argumentação e permite a avaliação crítica de reivindicações científicas e tecnológicas.

Apesar de haver mais de 40 anos da Educação Ciência-Tecnologia-Sociedade (Educação CTS) e cerca de 20 anos da Educação Científica a partir de Questões Sociocientíficas (QSC) no cenário internacional, a educação com base em QSC é incipiente no Brasil, ainda em crescimento enquanto campo de investigação. Quando consideramos o que é produzido no Brasil, o resultado é a escassez de materiais disponíveis sobre o uso de QSC para o ensino de ciências, principalmente de modo a

\footnotetext{
* Doutora em Educação. Professora da Faculdade de Ciências Exatas e Tecnologias da Universidade Federal da Grande Dourados (UFGD). Pesquisadora do Grupo EmTeia: Formação de Professores, Ambientalização Curricular e Educação em Ciências. E-mail: elisangelamiranda@ufgd.edu.br.
} 
fornecer subsídios teóricos e propostas de ensino aplicáveis tanto na educação básica quanto no ensino superior.

Dentro deste contexto, surge a obra Questões Sociocientíficas: fundamentos, propostas de ensino e perspectivas para ações sociopolíticas organizado por Dália Melissa Conrado e Nei Nunes-Neto. O livro contou com a colaboração de 46 pesquisadores que atuam em diferentes países, contribuindo com questões para aumentar a qualidade das investigações e implementações educacionais envolvendo processos de produção e aplicação de materiais sobre a Educação Ciência-Tecnologia-Sociedade-Ambiente (Educação CTSA) e a inserção das discussões sobre as QSC direcionadas para a formação de sujeitos mais críticos, participativos e capazes de tomar decisões e ações na sociedade.

Os autores são professores e pesquisadores que atuam no ensino superior brasileiro (Universidade Federal da Bahia, Universidade Federal de Goiás, Universidade Federal do Oeste da Bahia, Universidade Federal do Recôncavo da Bahia, Universidade Federal Rural do Rio de Janeiro, Universidade Federal do Tocantins, Universidade de Brasília, Universidade de São Paulo, Universidade do Estado da Bahia, Universidade Estadual de Feira de Santana, Universidade Estadual de Santa Cruz, Instituto Federal da Bahia) e professores e pesquisadores internacionais (Universidade de Auckland/NZ, Universidade de Iorque/CA, Universidade de Toronto/CA, Universidade de Lisboa/PT, Universidade Pedagógica e Tecnológica da Colômbia/CO, Universidade Pedagógica Nacional/CO, Universidade de Valência/ES), além de Docentes de Escolas da Educação Básica da Bahia, Bogotá (CO), e Ontário (CA).

No Prefácio, o Professor Irlan Von Linsingen aponta a relevância dessa temática e as oportunidades oferecidas por essa abordagem educacional para atingirmos uma educação crítica capaz de preparar sujeitos que reflitam e agem em prol de uma sociedade mais justa e sustentável. Neste sentido, o autor ressalta o caráter interdisciplinar da obra, que permite o diálogo entre diferentes cursos, disciplinas, grupos sociais, acadêmicos e não-acadêmicos, ampliando os pontos de vista sobre os problemas socioambientais atuais e a participação da comunidade para a sua resolução.

Nos capítulos 1, 2, 3, os autores discutem aspectos teóricos do ensino a partir de QSC, com ênfase sobre as dimensões ético-políticas da educação em ciências; a relevância do desenvolvimento de habilidades para o pensamento crítico na educação e da formação de indivíduos para ações sociopolíticas; além de explorarem caminhos, estratégias didáticas e métodos para maior aplicabilidade no uso de QSC no cotidiano escolar. Também são inseridas algumas questões de aprofundamento para pesquisadores da área, como a definição de pensamento crítico e sua importância, o estabelecimento de modelos teóricos para a implementação de QSC, entre outros.

Já entre os capítulos 4 e 17, são apresentadas propostas de ensino sobre temas variados, envolvendo disciplinas de física, química, biologia, geologia, entre outras. Os temas das QSC tratados nestes capítulos são: agronegócio e agrotóxicos; polinizadores e produção de alimentos; pesca da lagosta e conflitos socioambientais; poluição hídrica e ética ambiental; doença de Chagas e modelo socioecológico de saúde; tipos de próteses e aspectos sociocientíficos; consequências da medicalização da vida; impactos das terapias genéticas; rotulação de alimentos transgênicos; conceito de raça e composição étnica da população brasileira; urbanização e acesso à energia elétrica; geoengenharia do clima e responsabilidade social; exploração mineral e consumismo; energia nuclear e 
consequências socioambientais. Estas propostas de ensino podem ser adaptadas conforme os conteúdos que o docente pretende abordar, para diferentes níveis de escolaridade. Todos os capítulos seguem a mesma estrutura básica, a saber: discussão sobre a temática da QSC; introdução da QSC dentro de uma narrativa (caso); indicação de possíveis conteúdos a serem trabalhados, ligados a questões orientadoras que permitem alcançar determinados objetivos de aprendizagem para os estudantes. Os objetivos de aprendizagem estão organizados nas dimensões conceituais, procedimentais e atitudinais, de modo a potencializar a contextualização do conteúdo, permitindo uma aprendizagem mais integrada e, consequentemente, uma formação mais ampla dos estudantes.

Por fim, nos capítulos 18 a 23, são compartilhadas experiências com a educação baseada em QSC em diversos países. Os autores refletem sobre desafios e oportunidades para a implementação desta abordagem no currículo e no cotidiano escolar, como: a lacuna pesquisa-prática na educação; os resultados de pesquisas teóricas e empíricas; a importância do trabalho colaborativo, envolvendo diversos profissionais, para a elaboração de inovações educacionais; o incentivo à maior interação entre professores e licenciandos; a valorização do ativismo e do protagonismo juvenil, explicitando a articulação do conteúdo científico com aspectos sociais e ambientais, de modo que os estudantes possam refletir sobre seu papel na constituição de sociedades mais justas socioambientalmente.

Portanto, a obra Questões Sociocientíficas: fundamentos, propostas de ensino e perspectivas para ações sociopoliticas apresenta grandes contribuições teóricas e práticas ao indicar sugestões de ensino e traçar perspectivas para implementação no contexto escolar, além de relatar experiências do uso de QSC de modo cooperativo, em que se compartilham conhecimentos de modo interdisciplinar, habilidades, valores e práticas, estabelecendo condições que aumentam a possibilidade de sucesso na implementação da prática educativa direcionada para a formação de cidadãos mais preparados para lidar com as questões socioambientais contemporâneas. Neste sentido, recomenda-se a leitura deste livro por Estudantes, Pesquisadores e Educadores interessados em atualizar seus conhecimentos em aspectos teóricos e práticos sobre a educação baseada em QSC na perspectiva da Educação CTSA, ou que queiram aplicar as propostas e estratégias de ensino apresentadas, buscando uma melhor qualidade da educação científica e tecnológica em todos os níveis de ensino.

Recebido em: 15/12/2018

Aprovado em: 22/01/2019 